\title{
¿Son las personas mayores tan felices como las jóvenes? Limitaciones metodológicas de los análisis de regresión
}

\author{
¿Are old as happy as young people? Methodological constraints of \\ regression analysis
}

\section{EDUARDO BERICAT}

Universidad de Sevilla ebericat@us.es (ESPAÑA)

Recibido: 10.01 .2019

Aceptado: 22.04.2020

\section{RESUMEN}

El objetivo del artículo es responder a dos importantes preguntas relacionadas con la igualdad intergeneracional en bienestar emocional: $¿$ Son las personas mayores tan felices como las jóvenes? ¿Cuál es la relación entre edad y felicidad? El actual consenso académico considera que tal relación adopta la forma de una curva en "U", es decir, la felicidad sería alta en la juventud, descendería llegando a un mínimo hacia la mitad del curso vital, y remontaría hasta alcanzar de nuevo un alto nivel en la vejez. Según esta tesis, las personas mayores serían tan felices como las jóvenes.

Sin embargo, estos resultados están condicionados por las propias limitaciones metodológicas del análisis de regresión. Además, estos análisis pretenden describir la relación genérica y universal existente entre un concepto abstracto de edad y la felicidad. Pero como era previsible, la variable edad, desprovista de todo contenido social, tiene una escasa influencia en la felicidad de las personas. Estos estudios carecen de interés sociológico alguno porque ocultan la verdadera relación existente entre la "edad social" de las personas y su felicidad.

Tras exponer una crítica a los análisis de regresión, tal y como son habitual y convencionalmente aplicados por los científicos sociales, se propone segmentar la variable edad, estudiando el bienestar emocional de las personas en las distintas etapas de su ciclo vital (niñez, juventud, edad adulta, edad madura y vejez) utilizando análisis descriptivos multivariables. Se demuestra, así, que la relación edad-felicidad adopta la forma de una "ola" o "S" tumbada y que, por tanto, la felicidad de los mayores es bastante inferior a la de los jóvenes. 


\section{PALABRAS CLAVE} sión.

Felicidad, jóvenes, mayores, edad, bienestar emocional, análisis de regre-

\section{ABSTRACT}

The article aims to answer two important questions, both linked to emotional well-being throughout lifetime: Are old as happy as young people? What is the relationship between age and happiness? The current academic consensus states that the relationship between age and subjective well-being follows a «UShape». Happiness would be high in youngsters, would decrease to a minimum about midlife, and would ascend to reach again a high point in old age. Then, according to this thesis, old would be as happy as young people.

However, we show that these research results come from the own methodological constraints of regression analysis. Additionally, these analyses try to find the generic and universal relationship between age, considered as an abstract variable, and happiness. But, not surprisingly, an age variable devoid of any social content and context has a meagre influence on people happiness. These inquiries lack any sociological interest because hide more than reveal the actual relationship between "social age" and happiness.

The article deploys a critique of the irreflexive and conventional way in which regression analysis is used by social scientists. The segmentation of age in five stages (childhood, youthfulness, adulthood, maturity and old age), and descriptive multivariate analysis are proposed as the best methodology to study happiness throughout the lifetime. Finally, it is proved that the age-happiness relationship follows the pattern of a "wave" or "S lying down-shape". Therefore, the happiness of the old is much lower than that of young people.

\section{KEY WORDS}

Happiness, young people, old people, age, emotional well-being, regression analysis

\section{INTRODUCCIÓN ${ }^{1}$}

Debido a los múltiples vectores que están impulsando el cambio social en nuestras sociedades, y particularmente al incremento de la esperanza de vida y

${ }^{1}$ Agradezco a Luis Alfonso Camarero, a Francisco Perales, y a los revisores del artículo, sus excelentes comentarios. Sin duda, han contribuido a su mejora. Los errores que permanecen son exclusivamente míos. 
de los años de vida saludable, la tradicional configuración social de las edades y del curso vital está siendo sometida a muchas presiones. Todas las etapas de la vida, la niñez, la juventud, la edad adulta, la edad madura y la vejez están experimentando profundas transformaciones tanto en su contenido social como vivencial. Por ejemplo, la edad a la que un joven madura socialmente, inicia su trayectoria laboral, accede a una vivienda propia o forma una familia, cada vez se demora un poco más. La vejez, que ahora se prolonga durante un número mucho mayor de años, ha adquirido una naturaleza cultural, política, social y personal muy distinta a la vejez de épocas pasadas.

En este contexto, muchos ciudadanos, científicos sociales y responsables políticos comienzan a preguntarse en qué medida esta radical trasformación de la estructura etaria de nuestras sociedades está afectando a la situación social de los niños, jóvenes, adultos, maduros y mayores. Estos mismos agentes también se preguntan hasta qué punto se pueden estar creando o acrecentando desigualdades, injustificables, en las condiciones de vida de los diferentes grupos de edad. Informes recientes, inspirados en el principio de justicia intergeneracional, como por ejemplo Fairness for all ages?, elaborado por la organización benéfica Británica United for all ages, reclaman a los responsables políticos una actitud pro-activa a la hora de abordar las crecientes desigualdades entre jóvenes y mayores. La brecha entre las edades está afectando a muchos ámbitos, como la imposición fiscal que soportan respectivamente cada uno de estos grupos sociales, sus diferentes tasas de actividad laboral y condiciones de trabajo, el grado de acceso a una vivienda digna, o a su propiedad, su diferente grado de pobreza, nivel de ingresos y patrimonio, o el gasto en servicios públicos y asistencia social que la sociedad destina a cada una de las etapas de la vida.

Los estudios de desigualdad etaria han tratado muy diversos ámbitos y factores objetivos de la situación social. Sin embargo, apenas han considerado las desigualdades de bienestar subjetivo o emocional que tales factores sociales generan entre las personas de distinta edad. En este sentido, el presente artículo aporta una panorámica de las desigualdades de felicidad existentes en Europa entre las diferentes categorías de edad. El conocimiento de estas desigualdades es especialmente relevante porque la felicidad constituye un índice sintético del balance que establecen los propios individuos sobre su situación vital. De este modo, podemos llegar a saber si, desde la perspectiva vivencial de los propios individuos, existen grandes desigualdades derivadas del modo en que nuestras sociedades están re-configurando las edades y el curso de la vida. Es decir, los niveles de felicidad pueden cumplir una función de señal clave alertándonos de situaciones injustas que puedan estar creando sufrimiento social.

En este artículo hemos tratado de responder a dos importantes preguntas: ¿cuál es la relación entre edad y felicidad? y ¿son las personas mayores tan felices como los jóvenes? Según la revisión de la literatura realizada, el consenso académico actual sostiene que las personas mayores son tan felices como los jóvenes, y que la relación entre edad y felicidad adopta la forma de una "U". Esto significa que el nivel de felicidad de los jóvenes es alto, que desciende a un nivel mínimo en las personas de mediana edad, y que a partir de este punto 
vuelve a subir alcanzando en las personas mayores altos niveles de felicidad. Ahora bien, un análisis de las limitaciones metodológicas de los análisis de regresión mediante los que se han obtenido estos hallazgos contraintuitivos pone en cuestión esta supuesta "curva de la felicidad". La relación edad y felicidad adopta la pauta de una "S" tumbada. El artículo propone una estrategia analítica alternativa, el análisis descriptivo multidimensional, como la más idónea para analizar la estratificación social de la felicidad.

\section{EDAD Y FELICIDAD: UN ESTADO DE LA CUESTIÓN.}

Puede que el nivel de felicidad dependa en parte de la edad de las personas, pero también depende de otros muchos factores. Y dado que la edad está asociada diferencialmente con estos factores, es necesario aislar el efecto de la variable controlando, o manteniendo constantes, el resto de los factores. Dicho de otro modo, el análisis de la relación entre edad y felicidad implica aplicar el principio metodológico ceteris paribus ("siendo el resto de las cosas igual"). En general, las diversas técnicas analíticas asimilables a la regresión multivariante operan bajo este principio. De este modo pueden estimarse los efectos netos que tenga una variable, por ejemplo, la edad, sobre otra, la felicidad ¿Cuál es la relación, por tanto, entre la edad y la felicidad? La literatura académica nos ofrece diversas respuestas.

En 1999, Ed Diener, el prestigioso psicólogo experto en bienestar subjetivo, rechazaba la idea, defendida anteriormente por Wilson (1967), de que las personas mayores fueran menos felices. La satisfacción con la vida se mantiene; las emociones negativas no aumentan; $\mathrm{y}$, si acaso, disminuyen algo los estados emocionales positivos, que en las personas mayores suelen ser menos intensos, quizás debido al efecto de cohorte. En suma, la idea de que las personas de edad sean menos felices le parecía una sugerencia pesimista inaceptable (Diener, 1999:291).

Jivraj et al (2013) analizan datos de las cinco oleadas (2002-2011) del English Longitudinal Study of Ageing (2002-2011), que estudia a personas mayores de 50 años. En su estudio muestran que, controlando los factores más intensamente asociados con el bienestar subjetivo, como la salud y el estado civil, se observa una mejora de la felicidad desde los 50 hasta los 63 años, iniciándose a partir de aquí un período de declive acelerado de la felicidad, que se intensifica entre los más mayores o ancianos. Este acelerado declive puede reflejar, según los autores, "la entrada en los años finales de la vida" y, por tanto, estaría directamente relacionado con la proximidad de la muerte. Este rápido declive no está correlacionado con un deterioro del estado subjetivo de salud (Mroczek y Sapiro, 2005:195-5). Como conclusión, los autores sugieren "que la edad no es una causa determinante de bajos niveles de bienestar subjetivo" (Jivraj et al, 2013:11-12).

La relación curvilínea entre la edad y la felicidad, en forma de "U", implica que, una vez controlados otros factores, los niveles mínimos niveles de felici- 
dad se presentan en las edades medias de la vida. La edad exacta varía según los estudios, pero suele oscilar entre los 45 y 50 años. Darbonne et all (2013) apuntan que en la parte central del ciclo vital las personas están profundamente implicadas en roles laborales, familiares y cívicos, lo que conlleva la carga de sus múltiples responsabilidades. "La participación combinada en roles familiares y cívicos puede ser la causante de las mayores tensiones interpersonales que se observan en la mitad del curso de vida" (Darbonne et all, 2013:959). Por tanto, sería razonable pensar que las personas ya maduras, mayores de 55 años, una vez que abandonan el periodo de máxima implicación y saturación social, soporten menores niveles de tensión, lo que contribuiría a incrementar su bienestar emocional. También es posible que las personas maduras se hayan pertrechado de estrategias para afrontar estas situaciones de tensión y sean ahora más capaces de gestionarlas.

Beja (2018) analiza la relación entre edad y satisfacción con datos de la Encuesta Mundial de Valores, aunque truncando la muestra al intervalo de 15 a 69 años. Generando con los datos un pseudo panel, tomando como principales covariables la edad, el período y la cohorte, y aplicando un modelo de regresión multinivel, confirma que la relación adopta una forma de "U". Esto es, "la felicidad desciende desde un punto elevado en la juventud, alcanza un punto bajo en la mediana edad, y luego aumenta hasta alcanzar otro punto elevado en la vejez". Ahora bien, según este análisis "el punto elevado de felicidad en la vejez es más bajo que el punto elevando de la felicidad en la juventud" (Beja, 2018: 1817). Además, como muestran otros estudios (Schilling, 2006:267), Beja reconoce que el nivel de felicidad cae a partir de los 70 , debido a que problemas vinculados con la edad, como la salud y la inseguridad personal, condicionan negativamente la evaluación de la vida.

En conjunto, estos y otros estudios demuestran que la forma de "U" se adapta tan solo hasta los 75 años. El relativo repunte observado entre los 60 y los 74 años podría explicarse, retrospectivamente, por el efecto liberador derivado de la reducción de las tensiones vitales una vez que las personas dejan atrás el intenso período medio del curso de sus vidas. De ahí que, con una muestra poblacional truncada, que va de los 40 a los 85 años, Mroczek y Spiro (2005:194) observen una pauta de "U" invertida, con un máximo de satisfacción con la vida en torno a los 65 años. En efecto, esta pauta de "U" invertida también se aprecia si truncamos el Gráfico 3 a partir de los 50-55 años, pues el bienestar emocional asciende hasta los 60-64, para luego iniciar un descenso conforme avanza la edad.

Tanto Beja (2018:1825) como Blachflower y Oswald (2008:1746) reconocen que la evidencia proporcionada por los análisis de regresión no explica por qué la relación entre edad y felicidad adopta la forma de "U". En general, la literatura considera esta pauta como una paradoja, un rompecabezas o un misterio. En cualquier caso, en base a otras investigaciones, Beja (2018:1825) subscribe la idea de que la discrepancia entre aspiraciones y logros a lo largo del curso de la vida sería la explicación más plausible (Michalos, 1986; Schwandt, 2016; Lelkes, 2008). Esta discrepancia iría creciendo con los años hasta alcanzar un pico 
máximo a edades medias, precisamente cuando las preocupaciones materialistas (Kristoffersen, 2015) y las comparaciones sociales son más intensas.

A medida que van haciéndose mayores, las personas aprenden de sus experiencias moderando sus aspiraciones para ajustarlas a la situación real. Revisan su idea de la felicidad, abandonando la visión idealizada de la misma para adoptar una más sensata o realista. Las personas aprenden a manejar las situaciones de forma más sabia y eficiente, calibran con mayor precisión sus retos vitales, controlan más la frustración, y se resignan de mejor grado a sus condiciones de vida, sobre todo a partir de la edad madura. Según Lelkes (2008), la edad condiciona cambios en las aspiraciones y en las preferencias que tienden a incrementar su bienestar subjetivo, pero, simultáneamente, los cambios en las circunstancias de vida, por el contrario, tienden a disminuirlo. Pese a que las preferencias no cambian radicalmente a lo largo del curso de vida, puede decirse que las personas de mayor edad "son felices sobre todo porque modifican sus prioridades vitales" (Lelkes, 2008:7). En efecto, resulta fundamental tener en cuenta la combinación de aspiraciones y logros, ya que la felicidad no es una cantidad de algo, sino una relación entre la realidad de la vida y la potencialidad del ser (Bericat, 2018:80-84). Según el filósofo Emilio Lledó (2011:63), "La felicidad emerge de un permanente estado de vigilia en el que, a distintos niveles de conciencia, se plantea la necesidad de una correspondencia entre la posibilidad y la realidad, entre la armonía del cuerpo y el espacio histórico concreto, donde éste se desarrolla y alienta".

La relación entre edad y felicidad ha sido ampliamente debatida en la literatura, y aunque los distintos trabajos ofrecen resultados muy diversos, en general puede afirmarse que el consenso académico vigente sostiene que la relación entre edad y felicidad adopta la forma de "U". Los autores que con mayor consistencia y convicción han defendido esta hipótesis son Blanchflower y Oswald. En su reconocido trabajo de 2008, Is well-being U-shaped over the life cycle?, analizan 500.000 entrevistas procedentes de encuestas Norteamericanas y de Europa occidental para, controlando el efecto de cohorte, estimar la relación entre edad y felicidad. Manteniendo constante otros factores, aunque no el estado de salud, demuestran que la felicidad alcanza un mínimo, en ambos continentes, y tanto en hombres como en mujeres, en la mediana edad. Su investigación muestra que la forma de "U" aparece también cuando se analizan países del Este de Europa, Asia o América Latina.

En suma, la relación entre ambas variables no es lineal, sino curvilínea. Por eso los datos ajustan mejor cuando se aplica una función cuadrática que incluye, no solo la edad, sino también la edad al cuadrado. Los parámetros Beta de sus modelos, configurados con variables ficticias de intervalos quinquenales de edad, también muestran la citada pauta en forma de "U" (Blanchflower y Oswald, 2008: 1737). En su artículo de 2009, afirman que esta pauta también se mantiene, al igual que sucede en el Gráfico 2, cuando analizamos datos brutos (valores observados) sin aplicar ningún tipo de control.

Algunos autores, como por ejemplo Darbonne et al (2013), utilizan estos modelos de regresión para estimar valores esperados o predichos de felicidad, 
según edad. Su representación gráfica (Gráfico 1) revela claramente la pauta en forma de "U", lo que lleva a pensar que las personas mayores son tan felices como las jóvenes.

\section{Gráfico 1. Valores esperados de la Satisfacción con la vida, en función de la edad} en intervalos de 5 años (“0” representa la media a los 47 años).

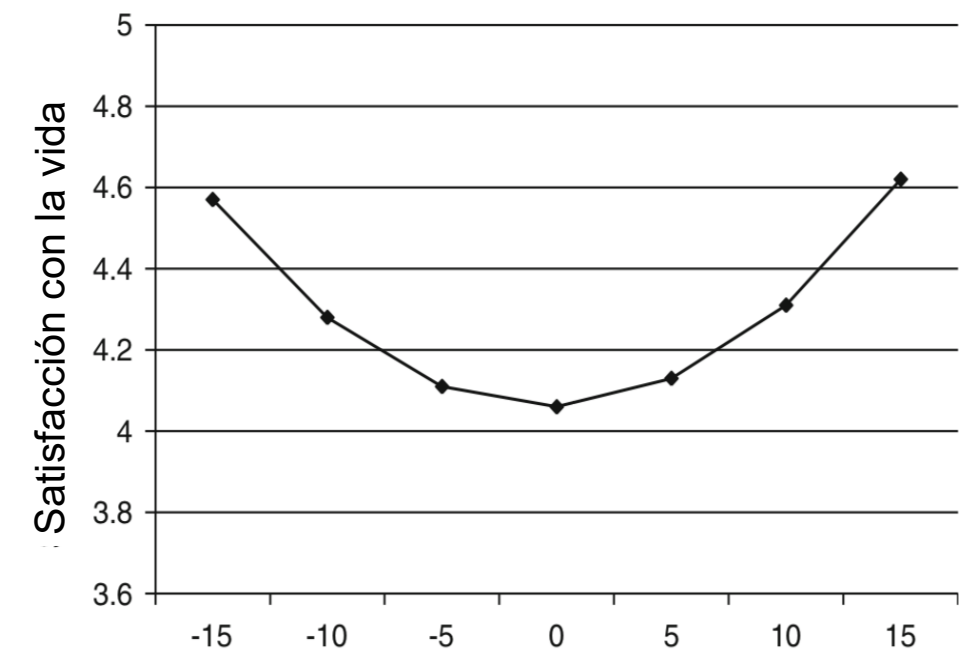

Fuente: Darbonne et al (2013: 957). Facsímil.

\section{3. ¿SON LAS PERSONAS MAYORES TAN FELICES COMO LAS JÓVENES?}

Un objetivo es estimar el efecto directo que tenga la edad sobre la felicidad, y otro muy distinto comprobar si las personas mayores son tan felices como las jóvenes. Para responder a esta pregunta usaremos los datos agregados de 27 países en las oleadas 2006 y 2012 de la Encuesta Social Europea².

La medición de la felicidad puede ser operacionalizada de muy diversas maneras, pero aquí utilizaremos dos de ellas, una cognitiva y otra afectiva. La más convencional consiste en preguntar al entrevistado en qué medida está satisfecho con su vida en general, ofreciéndole una escala en la que "0" significa extrema-

${ }^{2}$ Se utiliza esta gran muestra agregada con el objetivo de obtener la mayor fiabilidad y robustez posible. Los 27 países son: Albania, Austria, Bélgica, Bulgaria, Suiza, Chipre, Alemania, Dinamarca, Estonia, España, Finlandia, Francia, Reino Unido, República Checa, Holanda, Hungría, Italia, Irlanda, Islandia, Kosovo, Lituania, Noruega, Polonia, Portugal, Suecia, Eslovenia y Eslovaquia. 
damente insatisfecho, y "10" extremadamente satisfecho. Casi todos los análisis comentados en el epígrafe precedente

están basados en esta escala univariable de satisfacción con la vida, cuya naturaleza es básicamente cognitiva. La segunda medición de la felicidad que utilizaremos, de naturaleza básicamente afectiva, es el Índice de Bienestar Socioemocional (IBSE) diseñado por Bericat (2014). Este indicador compuesto se basa en la información aportada por el entrevistado sobre nueve estados emocionales, vinculados a cuatro dimensiones de la felicidad: tristeza, depresión, y soledad (vínculo); disfrute, y felicidad (situación); orgullo, y optimismo (persona); calma, y energía vital (control). En esta medición de la felicidad la persona no hace por sí misma un balance racional de su vida, sino que declara si se ha sentido triste, deprimido, sola, etc. durante la última semana. El grado de felicidad se estima aplicando el Análisis de Factor Común (AFC) al conjunto de respuestas, obteniéndose una escala que oscila entre -200 (mínima felicidad) y +100 (máxima felicidad) ${ }^{3}$. Este índice responde a un modelo multidimensional de la felicidad, en el que se tienen en cuenta las emociones relacionadas con cuatro dimensiones vitales de los individuos: las condiciones objetivas de vida (situación); la autoestima y fortaleza del sujeto (persona); el estado de sus relaciones sociales (vínculo); y el poder o capacidad de controlar las incertidumbres del entorno (control).

El Gráfico 2 muestra el nivel medio de satisfacción con la vida, según edad. La satisfacción desciende abruptamente del intervalo de 15-19 años al de 20-24, observándose a partir de los 25 una tendencia de descenso progresivo que alcanza hasta los 55-59 años. Pasados los 60, y hasta los 85-89, la satisfacción con la vida se mantiene en un nivel relativamente alto, similar al de los 30-34 años. Por último, vemos que la satisfacción crece abruptamente en las personas de 90 años y más. Observando la pauta general, podríamos concluir que las personas mayores son tan felices como los jóvenes. Un resultado inesperado y ciertamente contraintuitivo porque, en general, tendemos a creer que los jóvenes son muy felices y, en todo caso, bastante más felices que los mayores (Pichler, 2006).

${ }^{3}$ En Bericat (2014) se ofrece una explicación completa del marco teórico, operacionalización empírica e interpretación substantiva del IBSE. 


\section{Gráfico 2. Satisfacción con la vida (media), según edad. Europa-27, 2006+12.}

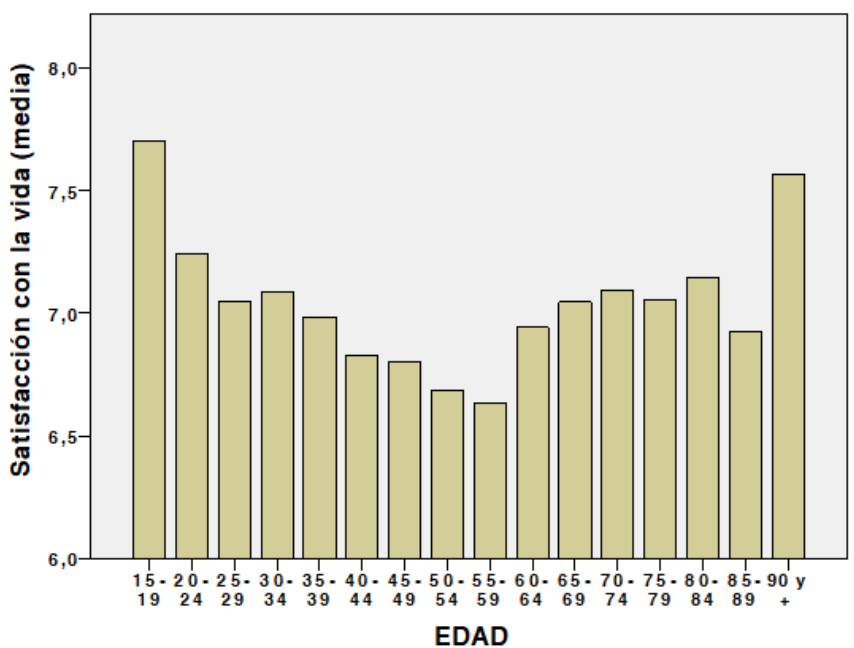

Fuente: Encuesta Social Europea, 2006+20124

El Gráfico 3 utiliza como medida de la felicidad el Índice de Bienestar Socioemocional (IBSE), y la pauta que muestra es muy diferente a la recién comentada. La felicidad desciende progresivamente, desde un punto muy elevado a los 15-19 años, hasta caer por debajo de la media (valor "0" en el gráfico) a partir de los 45 y hasta los 59. Sobre todo en los años que preceden a la jubilación (60-64), y durante los primeros años de ésta (65-74), se observa un ligero repunte del bienestar emocional, pero que en ningún caso alcanza los niveles de la juventud o los de la vida adulta hasta los 44 años. Finalmente, el IBSE muestra que a partir de los 75 años el bienestar emocional se desploma alcanzando, con mucha diferencia, los niveles más bajos de todo el curso vital. En suma, la pauta general del Gráfico 3 indica una reducción lineal y progresiva del bienestar emocional conforme avanza la edad, y demuestra que las personas mayores, sobre todo a partir de los 75 años, son bastante menos felices que las personas jóvenes y adultas.

${ }^{4}$ Todas la tablas y gráficos incluidos en el artículo, salvo los tres gráficos facsímiles, han sido elaborados por el autor utilizando datos de las oleadas 2006 y 2012 de la Encuesta Social Europea. 
Gráfico 3. Bienestar Socioemocional (IBSE) (media), según edad. Europa-27, $2006+12$.

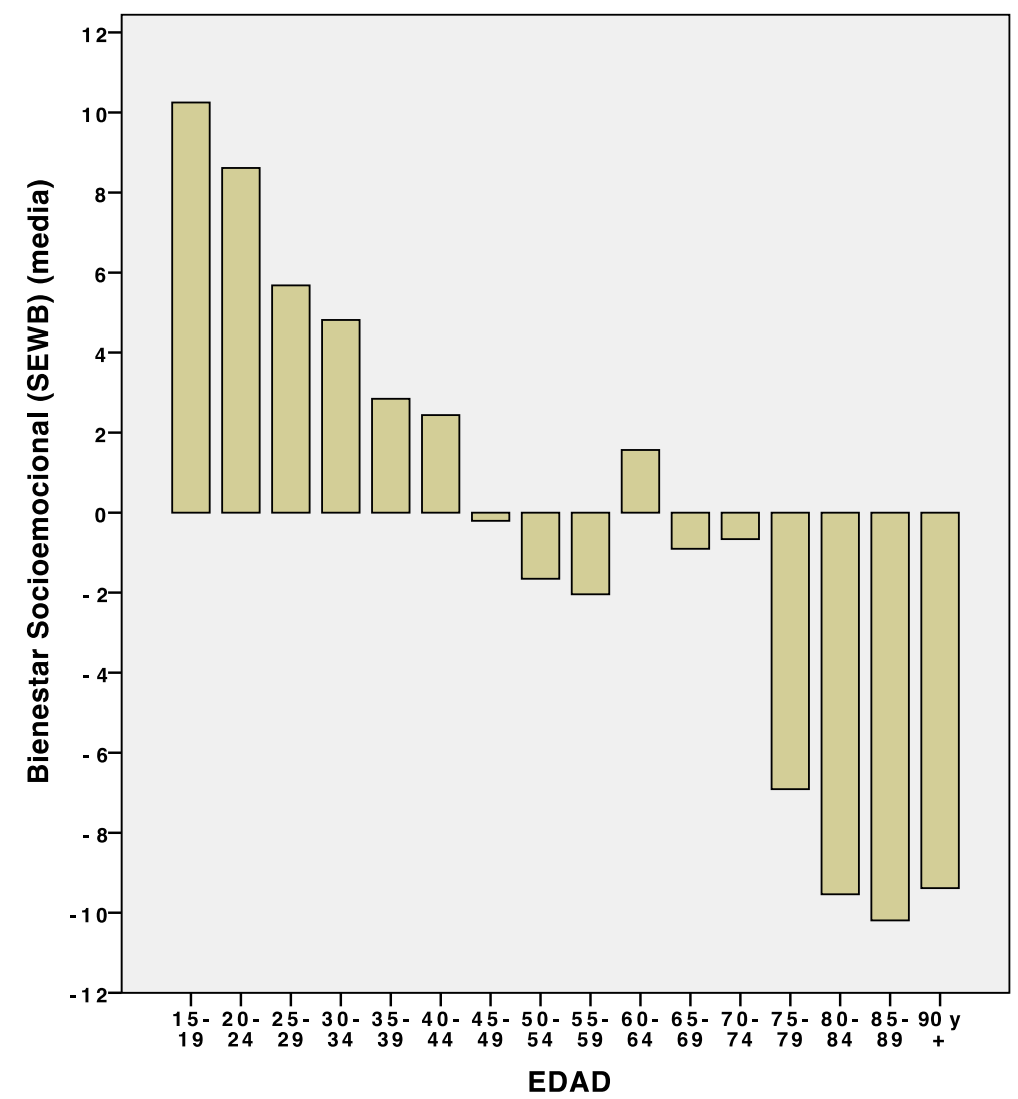

En síntesis, si el Gráfico 2 muestra que los mayores son tan felices como los jóvenes, el Gráfico 3 demuestra que los mayores son bastante menos felices que los jóvenes. En efecto, mientras que la pauta de satisfacción con la vida adopta una forma de "U", la del bienestar emocional se ajusta a una línea descendente con forma de "ola" o de "S" tumbada.

La discordancia entre estas pautas es evidente, poniendo de manifiesto, en primer lugar, la distinta naturaleza, cognitiva y afectiva, de ambas mediciones de la felicidad (Bericat, 2018:86-98; Vanhoute, 2012). La satisfacción con la vida constituye un balance, valoración o juicio racional que emite la propia persona entrevistada. Y a la hora de formar este juicio, el sujeto suele dar por hecho las circunstancias que caracterizan tanto su posición como su situación social. Dicho de otra manera, evalúa su vida sobre la base de una situación y unos grupos de referencia con los que se compara (Kemper, 2016). Así, por ejemplo, a la hora 
de emitir un juicio sobre su satisfacción, el presidiario tendrá en cuenta que está en prisión, y el inmigrante que tiene la condición de tal. En ambos casos puede que sobrevaloren su grado de satisfacción. Sin duda, la intensidad de este efecto es bastante menor cuando utilizamos una medida hedónica o afectiva de la felicidad, como es el Índice de Bienestar Socioemocional (IBSE). En segundo lugar, el IBSE integra un número de informaciones más amplio, robusto y complejo, aportando una medida de la felicidad más válida y fiable. En tercer lugar, muchos de los hallazgos que han aflorado en la revisión de la literatura realizada en el epígrafe anterior se ajustan a la pauta revelada por el IBSE (Gráfico 3), corroborando su validez.

Mediante una tipología creada en base a las puntuaciones del IBSE (Bericat, 2018:133-38) ofrecemos ahora una imagen más clara de cómo se distribuye la felicidad en las distintas etapas del curso vital. La Tabla 1 muestra el porcentaje de personas "felices", "contentas", "satisfechas", "insatisfechas" e "infelices", según edad.

Tabla 1. Tipología de la felicidad, según edad. Europa-27, 2006+12.

\begin{tabular}{|l|r|r|r|r|r|r|r|r}
\hline & \multicolumn{8}{c}{ EDAD } \\
\cline { 2 - 10 } & $15-24$ & $25-34$ & $35-44$ & $45-54$ & $55-64$ & $65-74$ & $75 y+$ & Total \\
\hline Feliz & 20,1 & 18,9 & 17,5 & 16,6 & 16,7 & 17,8 & 14,0 & 17,5 \\
\hline Contento & 34,6 & 31,6 & 31,5 & 28,7 & 29,6 & 28,1 & 24,6 & 30,2 \\
\hline Satisfecho & 31,5 & 32,6 & 32,5 & 33,9 & 32,9 & 32,3 & 34,8 & 32,9 \\
\hline Insatisfecho & 9,4 & 11,4 & 12,0 & 13,2 & 13,0 & 13,6 & 16,3 & 12,5 \\
\hline Infeliz & 4,5 & 5,5 & 6,6 & 7,6 & 7,8 & 8,2 & 10,3 & 7,0 \\
\hline Total & 100,0 & 100,0 & 100,0 & 100,0 & 100,0 & 100,0 & 100,0 & 100,0 \\
\hline
\end{tabular}

Entre las personas de 75 y más años hay casi el doble de "insatisfechos+infelices" (26,6\%) que entre los jóvenes de 15-24 años $(13,9 \%)$. A la inversa, el porcentaje de jóvenes "felices+contentos" $(54,7 \%)$ es bastante superior al de mayores $(38,6 \%)$. Ahora bien, estos datos también demuestran que ni todos los jóvenes son felices, ni todos los mayores infelices. Por último, al analizar la desviación típica del bienestar emocional en cada una de las edades, se comprueba que la heterogeneidad es mucho menor entre los jóvenes $(42,4)$ que entre los mayores $(50,0)$. Este dato es clave, y debe ser interpretado en el sentido de que la felicidad de los mayores es más dependiente de factores sociales que la de los jóvenes.

${ }^{5}$ Los umbrales y las medias de bienestar emocional de estos 5 tipos pueden verse en el Gráfico 6 . 


\section{ANÁLISIS METODOLÓGICO: LOS ESTUDIOS CORRELACIONALES Y EL PRINCIPIO CETERIS PARIBUS.}

¿Debemos dar por indubitables y ciertos los resultados de los estudios correlacionales realizados aplicando diversas técnicas de regresión? Algunos científicos sociales sostienen que estos resultados, como por ejemplo la mencionada pauta en "U", se explican en gran parte por la propia lógica del principio ceteris paribus subyacente a este tipo de análisis.

Para captar, de modo intuitivo, el efecto que tiene la aplicación de este principio proponemos al lector el siguiente experimento mental. Supongamos que las personas mayores de una sociedad sean más pobres, estén más enfermas y se sientan más solas. Supongamos, además, que los ingresos, la salud y la soledad influyen en la felicidad. En este contexto, si estimamos la felicidad de estas personas mediante un modelo de regresión que controle o mantenga constante el nivel de ingresos, el estado de salud y el grado de soledad, el resultado nos mostrará personas mayores "más felices" de lo que realmente son. La felicidad esperada o predicha por el modelo será necesariamente superior a la felicidad observada o real. En suma, lo que el modelo nos muestra es que, si estas personas mayores no fueran tan pobres, no estuvieran tan enfermas y no se sintieran tan solas, entonces su nivel de felicidad sería mayor, quizá tanto como el de los jóvenes. Sin embargo, el problema sociológico estriba en que en nuestras sociedades las personas mayores son realmente más pobres, están más enfermas y se sienten más solas. Por lo tanto, la aplicación del principio ceteris paribus, que calcula el efecto de la edad sobre la felicidad, haciendo que el resto de las condiciones de vida se mantengan igual o constantes, eleva artificialmente el nivel de felicidad de las personas mayores.

Cuando aplicamos estos análisis correlacionales y de regresión a otras relaciones, como la existente entre dinero y felicidad (Diener y Biswas-Diener, 2002), también obtenemos resultados paradójicos que requieren ser adecuadamente comprendidos. Así, la literatura académica sostiene que existe una débil correlación entre dinero y felicidad. Ahora bien, comparando el porcentaje de personas con bajos ingresos (primer quintil) que declaran sentirse muy felices $(37,9 \%)$, con el de las personas con altos ingresos (quinto quintil) $(70,4 \%)$, veremos que la probabilidad de ser feliz de los «ricos» es casi el doble que la de los «pobres» (Rojas, 2004: 8). Sociológicamente, la posición social de "rico", como asimismo la de "pobre", no se caracteriza en exclusiva por un determinado nivel de ingresos, sino por muchas más cosas. Los ricos tienen más dinero, pero también más estatus social, más salud, hacen más deporte, se alimentan mejor, alcanzan más logros, tienen un mayor nivel educativo, etc. Mantener constantes estos factores equivale a desnaturalizar lo que es "ser rico", equivale a querer saber qué efecto directo o neto tiene en sí mismo el dinero (¿de un avaro? ¿de una persona que solamente se distingue de las demás por la cantidad de dinero?) sobre la felicidad. Evidentemente, así considerado, el hecho de tener dinero, en sí mismo, tiene un efecto muy débil sobre la felicidad (Bericat, 2018:44). 
Idénticos argumentos podrían esgrimirse con respecto a la educación. Según el profesor Mikalos, si definimos la educación simplemente como nivel educativo, la felicidad como aquello que miden las escalas univariables de satisfacción o felicidad, y la influencia como efecto neto o directo, la influencia que ejerce la educación sobre la felicidad es evidentemente muy escasa. Ahora bien, si medimos la educación en todas sus variantes, concebimos de forma robusta el concepto de felicidad, y computamos como influencia todos los efectos, tanto los directos como los indirectos, entonces "la educación tiene una enorme influencia sobre la felicidad" (Michalos, 2008:348)

Frijters y Beaton (2012:530-31), además de comprobar, tanto en una revisión de la literatura como analizando tres encuestas panel, que los datos brutos presentan evidencias contradictorias a la hora de confirmar la hipótesis de la forma en "U", concluyen que, al menos en las encuestas alemana e inglesa, la forma de "ola" es una descripción más ajustada a la relación entre edad y felicidad. La reducción de felicidad de las personas mayores en estos dos países estaría en línea con la idea (Dear et al, 2002) de que las personas mayores declaran en menor medida niveles muy altos de felicidad. El trabajo de estos autores también tiene mucho interés porque aportan una prueba empírica del experimento mental propuesto anteriormente. Es decir, muestran en sendos gráficos qué le sucede a la relación edad-felicidad cuando es controlada introduciendo en el modelo un número cada vez mayor de factores.

El Gráfico 4 representa los valores observados o brutos según edad (línea gruesa continua), así como los valores esperados o predichos por dos regresiones de la satisfacción con la vida, una incluyendo la variable edad, y otra la edad y la edad al cuadrado. El Gráfico 5, además de mostrar los valores observados, representa los valores esperados por tres modelos de regresión, en los que la relación edad-felicidad es controlada cada vez por un mayor número de variables. Este último gráfico demuestra que cuantas más variables de control se introducen en el modelo, más se intensifica la pauta en forma de "U". En suma, cuanto más controlamos la relación edad-felicidad, mayor es el nivel de felicidad de las personas mayores estimado por el modelo, y menor el de las personas de mediana edad. 
Gráfico 4. Satisfacción con la vida, en la encuesta panel GSOEP (muestra integrada). Alemania. Valores observados, y esperados según dos modelos de regresión.
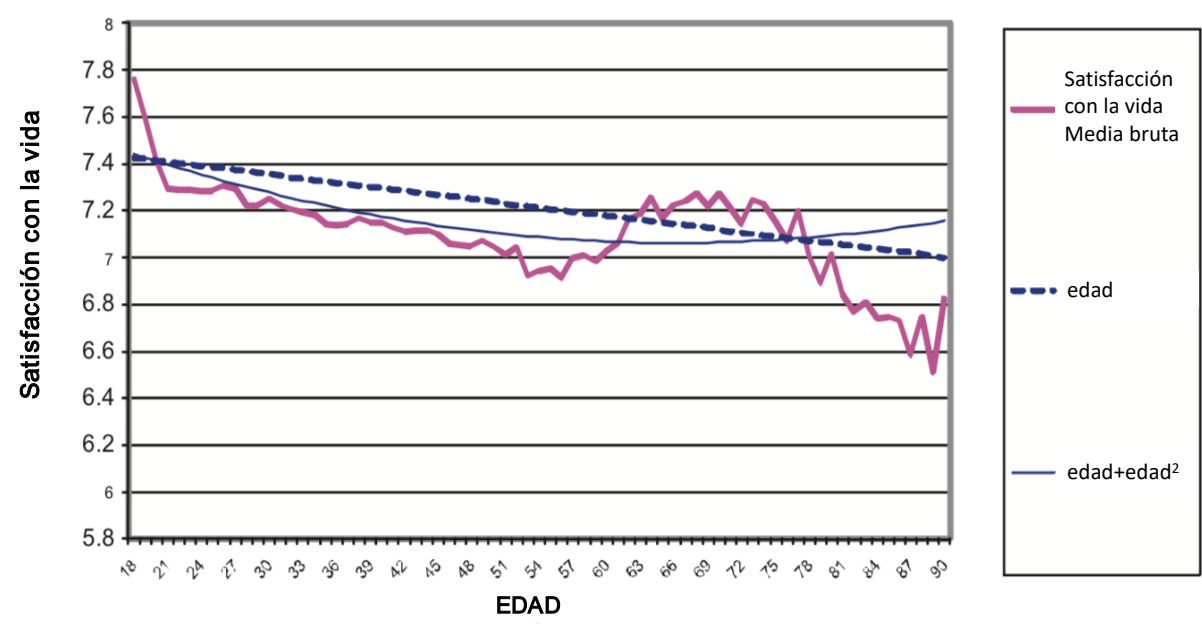

Fuente: Frijters, P. y Beatton, T. (2012:530). Facsímil.

Gráfico 5. Satisfacción con la vida en la encuesta panel GSOEP (muestra integrada). Alemania. Valores observados, y esperados según tres modelos de regresión.
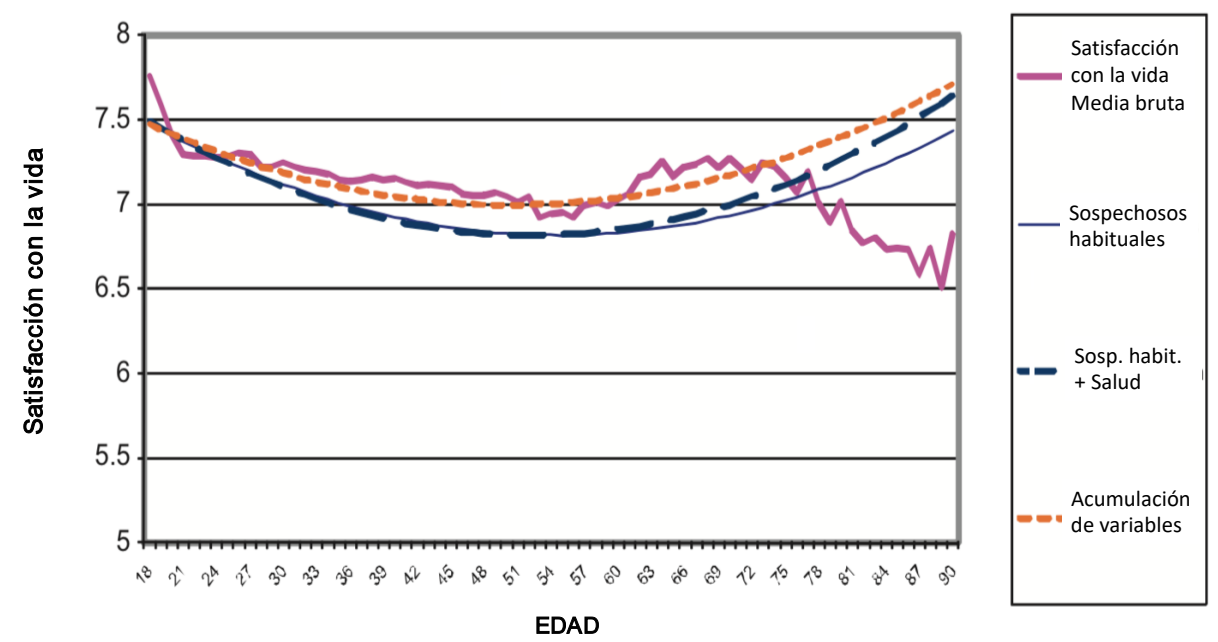

Fuente: Frijters, P. y Beatton, T. (2012: 532). Facsímil. 
Sospechosos habituales: ingresos, género, educación, número de niños, situación laboral, estado civil, etc.

Sosp. Habit. + Salud: Se añaden salud y patrimonio.

Acumulación de variables: Se añaden eventos vitales (divorcio, embarazo, muerte de familiar, etc.)

La línea gruesa continua en ambos gráficos representa los datos observados o brutos. La pauta de esta línea se asemeja al perfil de bienestar emocional representado en el Gráfico 3. La felicidad desciende progresivamente con la edad desde un elevando punto en la juventud hasta un nivel bajo a los 54-57 años; experimenta un incremento desde los 60 hasta los 74; para finalmente descender a partir de los 75, llegando a mínimos de satisfacción a los 90 años.

Los autores concluyen que el hecho de incluir en el modelo factores habitualmente utilizados en los análisis de regresión, los "sospechosos habituales", provoca una intensificación de la forma "U" (Frijters y Beatton, 2012:531). Este efecto también se detecta en otros estudios (Lelkes, 2008:2; Glenn, 2009:482). Además, con el objeto de comprobar si la forma de $\mathrm{U}$ puede ser debida a la causalidad inversa, es decir, al hecho de que las personas más felices, por el hecho de serlo, vivan más años, Frijters y Beaton estiman regresiones de efectos fijos. En este tipo de análisis, realizado con datos de encuestas panel, se tienen en cuenta los cambios de felicidad experimentados por un sujeto a lo largo del tiempo con respecto a su nivel base de felicidad. El resultado, en este caso, es que la pauta en forma de "U" de la relación entre edad y felicidad desparece por completo. Es decir, las personas mayores son menos felices que los jóvenes (Frijters y Beaton, 2012: 534-35).

\subsection{Crítica a los análisis de regresión}

En su comentario al renombrado artículo de Blanchflower y Oswald (2008), Glenn (2009) apunta tres reflexiones que sustentan una crítica al modo convencional y estandarizado en el que los científicos sociales desarrollan sus análisis de regresión con datos de encuesta. Esta crítica también contribuye a interpretar correctamente los resultados que ofrecen este tipo de estudios.

La primera reflexión alude a la necesidad de distinguir entre efectos directos, indirectos y totales, siendo estos últimos la suma de los directos y de cualquier efecto indirecto ejercido a través de otras variables incluidas en el modelo. Al mismo tiempo, Glenn advierte del error que supone creer que los efectos directos o netos de una variable son más importantes que sus efectos totales. Obviamente, esto depende de la pregunta o del problema en cuestión. Además, señala algo fundamental: "si todos los mecanismos por medio de los cuales ocurren los efectos pudieran ser identificados, representados en variables, y mantenidos constantes, las estimaciones de los efectos directos sería cero" (Glenn, 2009: 483). Es decir, si todos los mecanismos biológicos, psicológicos y sociales a través de los que la edad ejerce algún efecto sobre la felicidad fueran controlados, entonces el efecto directo de la edad sería nulo.

${ }^{6}$ La cursiva es mía. 
Esto nos enfrenta al problema conceptual planteado por Mikalos (2008): ¿Cuál es realmente el contenido que tiene la variable dependiente, la edad, en un determinado estudio? ¿Qué se entiende en ese estudio por "edad"? En efecto, al controlar la variable edad por todas aquellas otras variables sociales disponibles en nuestras encuestas estamos, inconscientemente, vaciando la edad de todo su contenido social. Entonces, quizás estemos calculando el efecto psicológico o biológico de la edad sobre la felicidad, pero en ningún caso el efecto de tener una determinada edad, en un determinado contexto social o sociedad. Lo que al sociólogo le interesa fundamentalmente es conocer, o descubrir, la relación que existe entre la "edad social" y la felicidad. Es decir, cómo influye sobre la felicidad el hecho de ser niño, joven, adulto, maduro o viejo.

La segunda reflexión alude al hecho de que "la mayor parte, si no todos los diversos periodistas que escribieron artículos acerca de la investigación de Blanchflower y Oswald interpretaron que los resultados de la regresión representaban lo que les sucede a las personas cuando envejecen, no lo que les hubiera sucedido si su estado civil y sus ingresos no hubieran cambiado conforme iban envejeciendo" (Glenn, 2009:483). Por ejemplo, La Vanguardia publicó en 2016 un artículo titulado "La otra curva de la felicidad: los mayores disfrutan más de la vida que los jóvenes" dores sociales que desarrollan estos análisis correlacionales incurren en errores parecidos, como evidencian algunas afirmaciones de sus artículos.

El error estriba en confundir, a) la experiencia subjetiva realmente experimentada o sentida por las personas, con b) la experiencia subjetiva que experimentarían esas mismas personas de encontrarse en una situación controlada y similar a la del modelo analítico. Es decir, se confunden los "valores observados" con los "valores esperados" por el modelo. El problema subyacente estriba en que las personas de carne y hueso no podemos experimentar la vida aplicándonos el principio ceteris paribus, es decir, prescindiendo de nuestro nivel de ingresos, estado de salud, estado civil, condición de autóctono o migrante, género, condiciones de trabajo, etc. Las personas sufrimos o disfrutamos de nuestras vidas en una experiencia total indisociable, pues no nos es dado controlar a voluntad los parámetros de nuestra situación vital. El error de confundir la felicidad realmente sentida por las personas de una determinada edad (valores observados o brutos), con los efectos directos de la variable edad, es también alentado por la práctica de representar gráficamente los valores esperados o predichos por el modelo (ver Gráfico 1), y no los parámetros Beta que indican la intensidad del efecto directo.

En su tercera reflexión, Glenn argumenta que los efectos totales "tienen una mayor importancia teórica y práctica que los efectos directos. Estos últimos no son muy útiles por sí mismos porque dependen mucho de las variables incluidas en el análisis, a través de la que se producen los efectos. Por ejemplo, las esti-

\footnotetext{
${ }^{7}$ La cursiva es mía.

${ }^{8}$ https://www.lavanguardia.com/vida/20160301/40120803932/curva-felicidad-mayoresdisfrutan-vida.html
} 
maciones de Blanchflower y Oswald cambiarían, probablemente de modo sustancial, si la variable salud física hubiera sido controlada" (Glenn, 2009: 483).

En efecto, la revisión de la literatura basada en análisis correlacionales y de regresión desconcierta casi siempre por la variedad de resultados que ofrece a tenor de los tiempos, espacios, modo de recopilar los datos, modelos y técnicas analíticas utilizadas, etc. De ahí que la interpretación de sus resultados deba tener muy en cuenta los efectos derivados del conjunto de variables que cada estudio haya introducido en su modelo.

\section{2. ¿Es la relación entre edad y felicidad universal?}

Los estudios realizados mediante análisis de regresión casi siempre asumen el supuesto de que la relación edad-felicidad es universal. Esto implica suponer que tal relación es independiente del contexto social, país, cultura, época, sistema socioeconómico, riqueza, desigualdad o calidad societal. Y se supone que, para revelar la existencia de esta relación universal, es necesario controlar o mantener constantes todos los factores sociales posibles. Sin embargo, al proceder de esta manera, como ya hemos visto, estamos vaciando la variable edad de todo contenido social.

En el caso de que concibiésemos la edad como una variable exclusivamente biológica tendría sentido preguntar si la relación edad-felicidad es universal. Pero la cuestión plantea serias dudas si pensamos que la edad y el curso vital son fenómenos construidos y estructurados socialmente. Por ello, con el fin de confirmar o rechazar la hipótesis de la universalidad, hemos calculado las medias del Índice de Bienestar Socioemocional (IBSE), para cada edad, en cada uno de los cinco grupos de países que conforman la Tipología de las Cinco Europas (Tabla 2), tipología que clasifica a los países según su grado de calidad societal (Bericat, 2019).

Tabla 2. Índice de Bienestar Socioemocional (IBSE) (media), según Tipo de las Cinco Europas y grupo de edad. Europa-27, 2006-12.

\begin{tabular}{lr|r|r|r|r|r|r|r|r} 
5 EUROPAS & $15-24$ & $25-34$ & $35-44$ & $45-54$ & $55-64$ & $65-74$ & 75 y + & Total & \multicolumn{1}{c}{ D } \\
\hline Nórdica & 12,4 & 14,4 & 11,4 & 11,8 & 14,2 & 15,8 & 8,3 & 12,8 & $\mathbf{4 , 1}$ \\
\hline Continental & 9,6 & 4,5 & 3,9 & 2,2 & 5,1 & 6,5 &,- 9 & 4,6 & $\mathbf{1 0 , 5}$ \\
\hline Mediterránea & 7,2 & 3,5 &,- 7 & $-7,8$ & $-9,3$ & $-11,3$ & $-20,9$ & $-4,5$ & $\mathbf{2 8 , 1}$ \\
\hline $\begin{array}{l}\text { Este de } \\
\text { Europa }\end{array}$ & 9,4 & 5,0 & $-2,4$ & $-9,9$ & $-16,1$ & $-24,4$ & $-26,1$ & $-6,6$ & $\mathbf{3 5 , 5}$ \\
\hline Balcanes & 17,8 & 5,2 & $-5,5$ & $-14,2$ & $-25,6$ & $-26,4$ & $-41,0$ & $-13,7$ & $\mathbf{5 8 , 8}$ \\
\hline Total & 9,4 & 5,2 & 2,6 &,- 9 &,- 3 &,- 8 & $-8,3$ & 1,5 & 17,7 \\
\hline
\end{tabular}


Los datos de la columna derecha de la Tabla 2 representan la diferencia (D) entre la felicidad de los jóvenes (15-24) y la de los mayores (75y+). En países con mayor calidad societal, como los nórdicos y continentales, la felicidad varía muy poco según edad. Al contrario, en países con menor calidad societal, como en el este de Europa o en los Balcanes, la diferencia de felicidad entre jóvenes y mayores es mucho más elevada. Vemos, pues, que el contexto social altera sensiblemente la relación entre edad y felicidad. Aplicado el mismo modelo de regresión de la Tabla 3 (ver anexo) a estas cinco Europas, comprobamos que los factores sociales pasan de explicar un $28,0 \%$ de la varianza de la felicidad en los países nórdicos, a explicar un 45,7\% en los balcánicos.

Por otra parte, los análisis de Morgan, Robinson y Thompson (2015) también demuestran que la relación edad-felicidad no es universal, sino que depende de la riqueza de las naciones. En los países ricos, los niveles de felicidad en las distintas edades son bastante similares, mientras que existen grandes diferencias en los países pobres. "Las oportunidades de empleo, las instalaciones de ocio, los servicios públicos, la disposición de pensiones y otros factores pueden contribuir al mantenimiento de la felicidad de los adultos mayores en los países ricos" (Morgan, Robinson y Thompson, 2015: 550). Pese a ser un país rico, el relativo bajo nivel de calidad societal de Estados Unidos quizás explique el hecho de que Easterlin (2006) encontrara allí una relación entre edad y felicidad que adopta la forma de una "U" invertida.

En conclusión, puede afirmarse que la relación entre edad y felicidad no es universal, sino que depende del contexto social.

\subsection{Edad y bienestar emocional}

La inmensa mayoría de los análisis de regresión que investigan la relación edad-felicidad utilizan como medida la escala univariable de satisfacción con la vida. A modo de contraste, hemos realizado una regresión lineal múltiple, por mínimos cuadrados ordinarios (MCO), que utiliza el Índice de Bienestar Socioemocional (IBSE) como medida de la felicidad. El modelo incluye cinco variables: edad; estado de salud; sentimiento de logro; respeto percibido; situación financiera; y actividad social. Estas variables han sido seleccionadas siguiendo el planteamiento de la teoría sociológica de la infelicidad, según la cual la falta de recursos económicos, respeto y sentido constituyen los factores sociales determinantes de la infelicidad (Bericat, 2018:35). También se incluyen los factores salud y actividad social, tan determinantes del bienestar emocional.

Observando en la Tabla 3 los coeficientes estandarizados (Beta) de los grupos quinquenales edad, que indican su efecto neto sobre la felicidad, comparado con el del grupo de 15-19 años, vemos que entre los 20-34 años no se aprecian diferencias estadísticamente significativas; los parámetros entre 35-54 años, la parte central del curso de vida, son negativos, lo que indica un descenso de la felicidad; entre los 55-59 se detecta un punto de inflexión y, en adelante, parámetros positivos y estadísticamente significativos entre los 60 y 74 años. 
Durante estos años la felicidad sube. Por último, como sucede en la juventud, los parámetros a partir de los 75 años tampoco son estadísticamente significativos, indicando que, cuando controlamos los principales factores de la felicidad, las personas mayores son tan felices como las jóvenes.

En conclusión, se confirma la hipótesis de que la variable edad, desprovista de contenido social, ejerce escasa influencia sobre la felicidad. La magnitud de los efectos asociados a los distintos grupos de edad es considerablemente más reducida que la del resto de factores. El modelo de la Tabla 3 explica un 32\% de la varianza del bienestar emocional $\left(\mathrm{R}^{2}=0,32\right)$. Si eliminamos la variable edad de este modelo, el coeficiente de determinación apenas disminuye $\left(\mathrm{R}^{2}=0,31\right)$, lo que demuestra su escasa incidencia, como bien han observado otros autores (Lelkes, 2008:1). Por ejemplo, Springer et al (2011), analizando la relación entre la edad y la escala de bienestar psicológico de Ryff, concluyeron que los cambios derivados de la edad son muy pequeños, pues explican tan solo entre un $1 \%$ y un $4 \%$ de la varianza, preguntándose finalmente si, dada su magnitud, tales cambios merecían la atención teórica recibida en la literatura académica.

\section{LAS EDADES Y LA ESTRATIFICACIÓN SOCIAL DE LA FELICIDAD.}

El conocimiento de la relación entre la variable "edad", desprovista de todo contenido social, y la felicidad, no contribuye en mucho al saber que las ciencias sociales deben aportar a los ciudadanos, agentes sociales y responsables políticos. Tampoco ayuda a diseñar políticas sociales específicamente orientadas al fomento de la justicia y de la solidaridad intergeneracional.

Las diversas edades o etapas del curso de vida son una construcción social y, por tanto, están socialmente estructuradas. De ahí que resulte sociológicamente inadecuado pensar que la edad opera como una variable continúa, medida al nivel de escala de razón. Por ejemplo, en una sociedad que rija la norma de jubilación a los 65, la diferencia entre tener 64 ó 65 años no es tan solo de una unidad. Equivale a un importante cambio vital: de trabajador en activo, a jubilado inactivo. Como bien saben los jóvenes, existe una gran diferencia entre tener 17 ó 18 años.

Esto explica por qué el estudio de la relación edad-felicidad debe desplegarse en cada una las principales etapas o edades en las que una sociedad segmenta el curso vital. La estructuración etaria de nuestras sociedades debe estudiarse analizando estas cinco grandes etapas: Infancia (0-14), Juventud (15-34), Edad adulta (35-54), Edad madura (55-75), y Vejez (75 y más).

La vivencia de la viudedad en un adulto es muy distinta a la que experimenta una persona mayor. Los estudios demuestran que las personas de mediana edad sufren mucho más intensamente las consecuencias vitales del desempleo (Winkelman and Winkelman, 1998). Carecer de un cierto nivel de ingresos afecta más a la felicidad de las personas de mediana edad. Sin embargo, una 
situación financiera complicada genera un malestar emocional más profundo en las personas mayores, ya que estas se sienten y son, por lo general, mucho más vulnerables. En términos culturales y existenciales no es lo mismo ser soltero a los treinta que a los cuarenta y cinco. Y, por supuesto, una persona mayor, sea hombre o mujer, vive la soledad de una forma radicalmente distinta a como la vive un joven adolescente, sea chico o chica.

Es suma, dado que existen abundantes efectos de interacción entre la edad y los factores sociales que inciden en la felicidad, es metodológicamente mucho más adecuado estudiar las "edades" que la variable "edad". La naturaleza, dirección e intensidad de los efectos de cualquier factor dependerán del grupo o categoría de edad analizada (Mroczek y Kolarz, 1998:1346), por lo que el análisis de la relación edad-felicidad debe segmentarse, y hacerse interseccional o mutidimensional. Por ello, sostenemos que la estrategia óptima para el estudio de la felicidad a lo largo del curso de vida es el análisis descriptivo multidimensional. Mediante la aplicación de metodologías cualitativas y cuantitativas, este análisis trataría de cumplir dos objetivos: a) conocer las vivencias, pautas y niveles de felicidad e infelicidad que experimentan niños, jóvenes, adultos, maduros y mayores, y b) explorar y descubrir los mecanismos y factores sociales específicamente determinantes del bienestar y malestar emocional en cada una de estas edades.

Las siguientes tablas y gráficos ilustran el proceder básico de este análisis descriptivo multidimensional o interseccional, orientado a responder, para cada categoría, tres tipos de preguntas: ¿cuán felices son? (distribución social de la felicidad y del sufrimiento); ¿cuántos son? (relevancia sociodemográfica); y ¿qué factores afectan su felicidad? (estructura correlacional). Como botón de muestra se ofrecen los datos del cruce "edad-salud" y de "edad-estado civil". Como es obvio, las categorías sociales a analizar en un completo estudio de estratificación intergeneracional de la felicidad podrían ser definidas por la intersección de más variables.

Para evaluar la relevancia sociodemográfica de cada categoría social (¿cuántos son?), se ofrece el porcentaje respecto de la población europea total mayor de 15 años (Tabla 4 y 8). Una información complementaria de gran interés es conocer la probabilidad de que las personas de una determinada edad tengan un determinado estado de salud o estado civil (Tabla 5 y 9). Con el fin de conocer sus niveles de felicidad (¿cuán felices son?) se ofrece el IBSE de cada una de las categorías (Tabla 6 y 10). Finalmente, teniendo en cuenta la importancia social que tiene el análisis del sufrimiento, se ofrece el porcentaje de personas "insatisfechas+infelices" (Tabla 7 y11). En conjunto, las cuatro tablas aportan una información sociológica básica y fundamental para conocer las desigualdades intergeneracionales de felicidad, existentes en Europa, en función del estado de salud y del estado civil. 
Tabla 4. Porcentaje de población total, según edades y estado subjetivo de salud. Europa-27, 2012.

\begin{tabular}{|l|c|c|c|c|c|}
\hline \multicolumn{7}{|c|}{ EDAD } \\
\hline Salud & $\begin{array}{c}\text { JÓVEN } \\
(15-34)\end{array}$ & $\begin{array}{c}\text { ADULTO } \\
(35-54)\end{array}$ & $\begin{array}{c}\text { MADURO } \\
(55-74)\end{array}$ & $\begin{array}{c}\text { MAYOR } \\
(75 \text { y más })\end{array}$ & TOTAL \\
\hline Muy buena & 9,9 & 7,4 & 3,3 &, 6 & 21,1 \\
\hline Buena & 12,8 & 17,4 & 11,7 & 2,4 & 44,3 \\
\hline Normal & 3,7 & 8,7 & 10,7 & 3,7 & 26,8 \\
\hline Mala & 0,6 & 1,7 & 2,9 & 1,4 & 6,5 \\
\hline $\begin{array}{l}\text { Muy mala } \\
\text { Total }\end{array}$ & 0,0 & 0,3 & 0,6 & 0,4 & 1,3 \\
\hline
\end{tabular}

Tabla 5. Porcentaje de población en cada edad, según estado subjetivo de salud. Europa-27, 2012.

\begin{tabular}{|c|c|c|c|c|c|}
\hline \multirow[b]{2}{*}{ Salud } & \multicolumn{4}{|c|}{ EDAD } & \multirow[b]{2}{*}{ TOTAL } \\
\hline & $\begin{array}{l}\text { JÓVEN } \\
(15-34)\end{array}$ & $\begin{array}{c}\text { ADULTO } \\
(35-54)\end{array}$ & $\begin{array}{c}\text { MADURO } \\
(55-74)\end{array}$ & $\begin{array}{l}\text { MAYOR } \\
\text { ( } 75 \text { y más) }\end{array}$ & \\
\hline Muy buena & 36,6 & 20,8 & 11,2 & 7,1 & 21,1 \\
\hline Buena & 47,4 & 49,1 & 40,1 & 28,1 & 44,3 \\
\hline Normal & 13,8 & 24,4 & 36,8 & 43,8 & 26,8 \\
\hline Mala & 2,1 & 4,8 & 9,9 & 16,6 & 6,5 \\
\hline Muy mala & 0,2 & 0,9 & 2,0 & 4,4 & 1,3 \\
\hline Total & 100,0 & 100,0 & 100,0 & 100,0 & 100,0 \\
\hline
\end{tabular}

Tabla 6. Nivel medio de felicidad (IBSE), según edad y estado subjetivo de salud. Europa-27, 2012.

\begin{tabular}{|l|c|c|c|c|c|}
\hline & \multicolumn{5}{|c|}{ EDAD } \\
\hline \multirow{2}{*}{ Salud } & $\begin{array}{c}\text { JÓVEN } \\
(15-34)\end{array}$ & $\begin{array}{c}\text { ADULTO } \\
(35-54)\end{array}$ & $\begin{array}{c}\text { MADURO } \\
(55-74)\end{array}$ & $\begin{array}{c}\text { MAYOR } \\
(75 \text { y más })\end{array}$ & TOTAL \\
\hline Muy buena & 25,28 & 24,74 & 30,86 & 34,33 & 26,21 \\
\hline Buena & 6,39 & 5,09 & 13,57 & 16,67 & 8,32 \\
\hline Normal & $-13,41$ & $-12,47$ & $-7,61$ & $-6,75$ & $-9,87$ \\
\hline Mala & $-40,15$ & $-40,80$ & $-37,16$ & $-38,23$ & $-38,59$ \\
\hline $\begin{array}{l}\text { Muy mala } \\
\text { Total }\end{array}$ & $(-97,46)$ & $-57,42$ & $-60,11$ & $-77,54$ & $-65,74$ \\
\hline
\end{tabular}


Tabla 7. Porcentaje de "insatisfechos+infelices", según edad y estado subjetivo de salud. Europa-27, 2012.

\begin{tabular}{|c|c|c|c|c|c|}
\hline & \multicolumn{4}{|c|}{ EDAD } & \\
\hline Salud & $\begin{array}{l}\text { JÓVEN } \\
(15-34)\end{array}$ & $\begin{array}{c}\text { ADULTO } \\
(35-54)\end{array}$ & $\begin{array}{c}\text { MADURO } \\
(55-74)\end{array}$ & $\begin{array}{l}\text { MAYOR } \\
\text { (75 y más) }\end{array}$ & TOTAL \\
\hline Muy buena & $7,0 \%$ & $8,5 \%$ & $6,3 \%$ & $3,1 \%$ & $7,3 \%$ \\
\hline Buena & $16,0 \%$ & $15,9 \%$ & $11,6 \%$ & $7,2 \%$ & $14,3 \%$ \\
\hline Normal & $29,2 \%$ & $27,2 \%$ & $24,7 \%$ & $24,4 \%$ & $26,1 \%$ \\
\hline Mala & $50,9 \%$ & $52,6 \%$ & $49,5 \%$ & $49,0 \%$ & $50,3 \%$ \\
\hline Muy mala & $88,6 \%$ & $55,8 \%$ & $63,3 \%$ & $76,5 \%$ & $66,1 \%$ \\
\hline Total & $15,4 \%$ & $19,2 \%$ & $20,6 \%$ & $24,4 \%$ & $19,0 \%$ \\
\hline
\end{tabular}

Del análisis detallado de estas tablas, que no podemos ofrecer aquí por falta de espacio, pueden extraerse informaciones sociológicas muy interesantes. Por ejemplo, la Tabla 4 demuestra que la edad madura aporta la mayor cantidad de personas $(14,2 \%)$ con algunos problemas de salud (normal, mala, muy mala), más del doble que las personas mayores $(5,5 \%)$ y que las jóvenes $(4,7 \%)$. En general, se confunden estos datos, que indican la distribución poblacional de una característica, con la probabilidad que tienen las personas de una determinada edad de estar enfermas o sanas. Así, en la Tabla 5 vemos que el 64,8\% de los mayores no gozan de buena o de muy buena salud o que, al contrario, el 84,0\% de los jóvenes declaran tener muy buena o buena salud.

La Tabla 6 revela, por ejemplo, que el nivel de felicidad de las personas maduras y mayores que gozan de muy buena salud es superior al de los jóvenes con muy buena salud. Estos datos sugieren la idea de que quizás las personas de cierta edad valoren mucho más la salud que los jóvenes, que la dan por supuesta. A la inversa, teniendo en cuenta el nivel medio de felicidad de cada edad, se comprueba que la mala salud en los jóvenes provoca una relativamente mayor infelicidad que en los mayores, lo que indica la existencia de interacción entre las variables. Un mismo factor, en este caso la salud, tiene en las distintas edades consecuencias diferentes sobre la felicidad. En la fila de totales de la Tabla 7 puede verse que el porcentaje de mayores "insatisfechos+infelices" $(24,4 \%)$ supera en nueve puntos al de los jóvenes $(15,4 \%)$. También sorprende comprobar que un estado subjetivo de salud "muy malo" incrementa dramáticamente el número de "insatisfechos+infelices" en las personas mayores (76,5\%); no tanto en los adultos $(55,8 \%)$ o en las personas maduras $(63,8 \%)$; pero aún más en los jóvenes $(88,6 \%)$.

El estudio interseccional o muldimensional de la relación edad-felicidad, sea analizando la salud subjetiva (Tablas 4 a 7), el estado civil (Tablas 8 a 11), $\mathrm{u}$ otras variables que podrían seleccionarse (ingresos económicos, soledad, actividad laboral, etc.), muestran que muchos rasgos de la situación social de las personas están muy desigualmente distribuidos a lo largo del curso vital. El conocimiento de sus respectivos niveles de felicidad permite comprobar hasta qué punto estos rasgos comportan desigualdades emocionales, es decir, si las formas 
objetivas de estratificación social se manifiestan en una estratificación social del bienestar subjetivo. Saber, por ejemplo, que el $37,1 \%$ de las personas mayores en Europa son viudas (Tabla 9), mujeres en su mayor parte; que su nivel medio de felicidad es muy bajo, IBSE $=-16,8$ (Tabla10); o que una de cada tres $(32,8 \%)$ viven "insatisfechas" o "infelices", hace que comprendamos mucho mejor la situación vital, tanto objetiva como subjetiva, de las mujeres mayores viudas. También nos ayuda a valorar este problema social, así como a diseñar y promover las debidas políticas de apoyo social.

Para concluir, como muestra empírica del experimento mental propuesto al lector, así como del estudio de los factores y de la estructura correlacional en cada etapa del ciclo vital, el Grafico 6 muestra el efecto combinado que tienen sobre la felicidad de las personas mayores la salud, la soledad y la pobreza. En el gráfico se indica el nivel medio del IBSE para cada una de las categorías de persona mayor definida multidimensionalmente. Los mayores que tienen muy mala salud, se sienten solos, y son pobres ("MMS+solo+pobre") tienen un IBSE= $-130,7$, es decir, experimentan sus vidas desde una profunda infelicidad. Si su salud es mala ("Mala salud"), su nivel de infelicidad se reduce bastante (IBSE= $-41,9)$, aunque estos mayores siguen perteneciendo al tipo de los "insatifechos". Al contrario, cuando disfrutan de muy buena salud y no están solos, su felicidad se eleva bastante por encima de la media (IBSE $=+39,6$ ), llegando al límite entre los "contentos" y los "felicies".

En suma, el análisis descriptivo multidimensional no ofrece una única respuesta a la pregunta sobre la relación edad-felicidad, sino que se despliega explorando los múltiples matices que tal relación adopta a lo largo del curso de la vida. Es una estrategia metodológica para el estudio de la relación edadfelicidad, sin perder de vista ni las vivencias afectivas personales, ni las lógicas sociales que las vertebran. 
Gráfico 6. Felicidad (bienestar socioemocional, IBSE) de las personas mayores de 75 y más años, según salud, soledad e ingresos económicos. Europa-27, 2012.

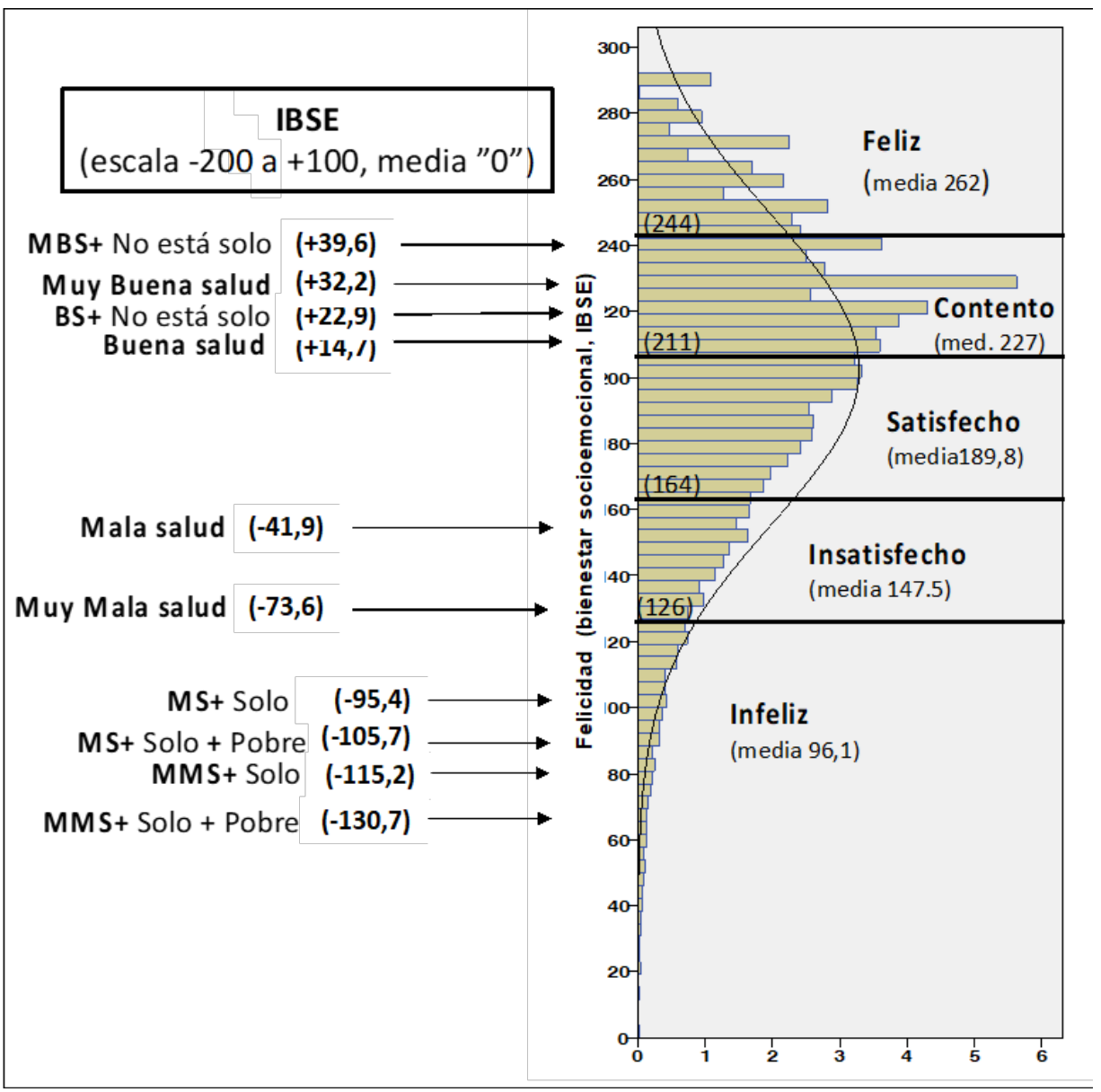

\section{CONCLUSIONES}

\section{A) Limitaciones metodológicas de los análisis de regresión.}

La revisión de investigaciones sociales que estudian la relación edad-felicidad ha revelado deficiencias metodológicas del uso que se hace de los análisis de regresión.

1. Es inadecuado trabajar con un concepto indefinido y abstracto de edad, vacío o carente de todo contenido y contexto social. El contenido de las eda- 
des del curso de vida, o "edad social", viene determinado en cada sociedad y época por las estructuras institucionales que lo configuran. Es decir, todo análisis de regresión debe definir conceptualmente, con precisión y claridad, el fenómeno objeto de estudio.

2. Los análisis de regresión revisados conciben la edad como una variable continua medida al nivel de escala de razón. Ahora bien, sociológica, psicológica, económica, biológica, política y humanamente, es más adecuado estudiar la edad segmentándola en etapas del curso vital. El reto es analizar la felicidad de niños, jóvenes, adultos, maduros y mayores, comprendiendo sus específicos factores y mecanismos sociales determinantes.

3. Los análisis de regresión asumen implícitamente que la relación edad-felicidad es universal. En la práctica, este supuesto abstrae aún más el contenido de la variable edad, obviando que tal relación depende del contexto social. Hemos demostrado, por ejemplo, que la diferencia entre el nivel de felicidad de los mayores y el de los jóvenes depende de la calidad societal.

4. Los análisis de regresión, si bien suelen presentarse a sí mismos como análisis causales o explicativos, son en verdad análisis descriptivos multivariantes, esto es, análisis correlacionales. La mayoría de estos análisis adolecen de: una teoría social bien fundamentada; una conceptualización precisa y robusta; una operacionalización empírica valida y fiable; un diseño metodológico explicativo o causal; unas hipótesis específicas y relevantes; y unas pruebas empíricas confirmatorias suficientemente sólidas.

5. Al analizar un fenómeno social, como la relación edad-felicidad, es importante conocer todos los efectos, no solo los directos e indirectos, sino también los efectos totales. Al igual que Amartya Sen (1980) o Mike Savage y Rogers Borrows (2007), no comparto en absoluto el desdén con el que bastantes investigadores sociales tratan la "descripción". Primero, porque descripción y explicación son dos tareas indispensables del quehacer científico. Segundo, porque están mutuamente implicadas, ya que sin una adecuada descripción de los hechos es imposible alcanzar una buena explicación.

En suma, en la investigación social actual, la aplicación rutinaria, convencional e irreflexiva de las técnicas estadísticas de análisis de regresión tiende a desplazar tanto a la ciencia como al pensamiento.

\section{B) La felicidad a lo largo del curso de la vida}

1. La relación edad-felicidad no adopta, como sostiene el consenso académico actual, la forma de una "U", sino más bien la de una "ola" o "S" tumbada (Un). El nivel de felicidad durante la juventud (15-35) es relativamente alto; desciende en la edad adulta (35-54); repunta ligeramente en la madurez (5574) sin alcanzar los niveles de la juventud; y vuelve a descender en la última etapa de la vida, a partir de los 75 . 
2. Está científicamente demostrado que el efecto directo de la edad biológica (edad carente de todo contenido social) sobre la felicidad, es incomparablemente más pequeño que el de otros factores sociales, como la soledad, los recursos económicos, el estado de salud o la falta de sentido.

3. El método más adecuado para investigar la distribución social de la felicidad y de la infelicidad, así como la equidad afectiva o emocional, es el análisis descriptivo multidimensional. El bienestar emocional observado en las personas de carne y hueso constituye la base empírica ineludible para el desarrollo de una estratificación social de la felicidad. Esta estrategia analítica permite revelar categorías sociales, en el seno de las distintas edades, caracterizadas por diferentes niveles, pautas y factores de felicidad e infelicidad. Mediante el análisis descriptivo multidimensional, que incluye análisis correlacionales, también se puede descubrir la peculiar configuración de factores y mecanismos causales que operan en el seno de estas categorías.

4. El conocimiento descriptivo y correlacional que aporta esta estrategia metodológica debe inspirar y sustentar las políticas y programas sociales orientados, fundamentalmente, a reducir la infelicidad de todas aquellas personas que sufren. En efecto, aunque la edad biológica de las personas sea inmodificable, siempre podremos intervenir sobre los principales factores y mecanismos sociales causantes del dolor, el sufrimiento y el malestar emocional.

5. Si, como hemos visto, los factores sociales son determinantes del grado de felicidad o infelicidad, y el bienestar emocional depende de la calidad de las sociedades, debemos repensar y reevaluar el estado de la justicia afectiva intergeneracional. ¿Son justas las desigualdades de felicidad entre las diversas edades? ¿Debería ser uniforme, o no, el nivel de felicidad a lo largo de todo el ciclo vital? ¿Tienen algunos grupos de edad, por ejemplo, los jóvenes, más derecho a la felicidad que otros, por ejemplo, las personas mayores, o viceversa? ¿Existen criterios éticos o morales mediante los que podamos distinguir entre desigualdad y equidad emocional? ¿En qué condiciones afirmaremos que una sociedad está cohesionada afectivamente? ¿Qué beneficios se derivan de la equidad y de la cohesión emocional?

En suma, la gran trasformación social a la que se enfrenta nuestra sociedad global implica necesariamente una profunda remodelación de su estructura etaria. De ahí que la investigación social sobre las edades y el curso de la vida deba ir más allá del estudio de sus dimensiones objetivas, incorporando también las subjetivas y emocionales. El estudio sociológico de la felicidad nos permite monitorizar en todo momento cómo las personas evalúan su vida y, de este modo, nos ofrecen señales acerca de los efectos que las lógicas y las estructuras sociales están ejerciendo sobre ellos. 


\section{ANEXO}

Tabla 3. Regresión lineal múltiple (MCO) del bienestar socioemocional por edad, estado de salud, sentimiento de logro, respeto percibido, situación financiera, y actividad social. Europa-27, 20106-12.

\begin{tabular}{|c|c|c|c|c|c|}
\hline \multirow[b]{2}{*}{ Modelo } & \multicolumn{2}{|c|}{$\begin{array}{l}\text { Coeficientes no } \\
\text { estandarizados }\end{array}$} & \multirow{2}{*}{$\begin{array}{c}\begin{array}{c}\text { Coeficientes } \\
\text { estandarizados }\end{array} \\
\text { Beta } \\
\end{array}$} & \multirow[b]{2}{*}{$t$} & \multirow[b]{2}{*}{ Sig. } \\
\hline & B & $\begin{array}{c}\text { Error } \\
\text { estándar }\end{array}$ & & & \\
\hline (Constante) & $-10,52$ &, 30 & & $-34,95$ & ,000 \\
\hline Edad 20-24 &, 57 &, 58 &, 004 & ,98 &, 326 \\
\hline Edad 25-29 & ,24 &, 58 &, 002 &, 41 & ,680 \\
\hline Edad 30-34 &,- 82 &, 55 &,- 007 & $-1,49$ & , 136 \\
\hline Edad 35-39 & $-2,29$ &, 53 &,- 019 & $-4,29$ &, 000 \\
\hline Edad 40-44 & $-1,10$ &, 50 &,- 009 & $-2,19$ &, 029 \\
\hline Edad $45-49$ & $-2,12$ &, 50 &,- 018 & $-4,25$ &, 000 \\
\hline Edad 50-54 & $-2,12$ &, 51 &,- 018 & $-4,17$ &, 000 \\
\hline Edad 55-59 &,- 92 &, 53 &,- 008 & $-1,75$ &, 080 \\
\hline Edad 60-64 & 1,92 &, 55 &, 016 & 3,53 &, 000 \\
\hline Edad 65-69 & 1,17 &, 58 & ,009 & 2,01 &, 045 \\
\hline Edad 70-74 & 3,52 & ,64 & ,026 & 5,52 &, 000 \\
\hline Edad 75-79 & 1,34 & ,73 & ,009 & 1,84 & ,066 \\
\hline Edad $80-84$ &,- 09 & ,91 &,- 001 &,- 09 & ,926 \\
\hline Edad 85-89 & $-1,70$ & 1,35 &,- 010 & $-1,26$ & ,207 \\
\hline Edad 90 y mas & 1,84 & 2,50 &, 010 & ,74 & ,461 \\
\hline Salud Buena & 9,01 & ,24 &, 150 & 37,10 &, 000 \\
\hline Salud Normal & $-4,49$ &, 27 &,- 066 & $-16,54$ &, 000 \\
\hline Salud Mala/Mmala & $-25,87$ &, 43 &,- 290 & $-59,77$ &, 000 \\
\hline Logro Sí (M acuerdo) & 18,24 &, 28 & ,288 & 64,19 &, 000 \\
\hline Logro No (Ni/desac/Md) & $-20,84$ &, 25 &,- 384 & $-84,12$ &, 000 \\
\hline Respeto Si (6) & 8,79 &, 29 &, 125 & 30,51 &, 000 \\
\hline Respeto Sí (5) & 3,81 &, 23 &, 064 & 16,60 &, 000 \\
\hline Respeto No $(0,1,2,3)$ & $-10,76$ &, 30 &,- 149 & $-35,82$ &, 000 \\
\hline Ingresos (cómodos) & 12,36 &, 30 &, 229 & 41,88 &, 000 \\
\hline Ingresos (dificultades) & $-3,23$ & ,33 &,- 052 & $-9,92$ &, 000 \\
\hline Ingresos (Muchas dific.) & $-16,63$ &, 52 &,- 209 & $-31,76$ &, 000 \\
\hline Act. Sociales (Más/Mmás) & 8,39 &, 31 &, 133 & 27,33 &, 000 \\
\hline Act. Sociales (Menos) & $-2,67$ &, 27 &,- 047 & $-10,07$ &, 000 \\
\hline Act. Sociales (Mmenos) & $-10,23$ & ,37 &,- 145 & $-27,48$ &, 000 \\
\hline
\end{tabular}

a. Variable dependiente: Índice de Bienestar Socioemocional (IBSE) 
Tabla 8. Porcentaje de población total, según edades y estado civil. Europa-27, 2012.

\begin{tabular}{|c|c|c|c|c|c|}
\hline & \multicolumn{4}{|c|}{ EDAD } & \\
\hline Estado civil & $\begin{array}{l}\text { JÓVEN } \\
(15-34)\end{array}$ & $\begin{array}{c}\text { ADULTO } \\
(35-54)\end{array}$ & $\begin{array}{c}\text { MADURO } \\
(55-74)\end{array}$ & $\begin{array}{l}\text { MAYOR } \\
\text { (75 y más) }\end{array}$ & TOTAL \\
\hline Casado/Pareja & $5,3 \%$ & $23,9 \%$ & $20,8 \%$ & $4,4 \%$ & $54,4 \%$ \\
\hline Separado & $0,0 \%$ & $0,3 \%$ & $0,2 \%$ & $0,0 \%$ & $0,6 \%$ \\
\hline Divorciado & $0,3 \%$ & $3,5 \%$ & $2,7 \%$ & $0,4 \%$ & $6,9 \%$ \\
\hline Viudo & $0,0 \%$ & $0,4 \%$ & $3,2 \%$ & $3,1 \%$ & $6,8 \%$ \\
\hline $\begin{array}{l}\text { Nunca casado / } \\
\text { Otros }\end{array}$ & $20,7 \%$ & $6,9 \%$ & $1,8 \%$ & $0,4 \%$ & $29,8 \%$ \\
\hline DK/NA & $0,5 \%$ & $0,4 \%$ & $0,4 \%$ & $0,1 \%$ & $1,5 \%$ \\
\hline Total & $27,0 \%$ & $35,5 \%$ & $29,1 \%$ & $8,4 \%$ & $100 \%$ \\
\hline
\end{tabular}

Tabla 9. Porcentaje de población en cada edad, según estado civil. Europa-27, 2012.

\begin{tabular}{|l|c|c|c|c|c|}
\hline & \multicolumn{5}{|c|}{ EDAD } \\
\hline & $\begin{array}{c}\text { JÓVEN } \\
(15-34)\end{array}$ & $\begin{array}{c}\text { ADULTO } \\
(35-54)\end{array}$ & $\begin{array}{c}\text { MADURO } \\
(55-74)\end{array}$ & $\begin{array}{c}\text { MAYOR } \\
(75 \text { y más) }\end{array}$ & TOTAL \\
\hline Estado civil & $19,7 \%$ & $67,2 \%$ & $71,5 \%$ & $52,3 \%$ & $54,4 \%$ \\
\hline $\begin{array}{l}\text { Casado/Pareja } \\
\text { Separado }\end{array}$ & $0,2 \%$ & $1,0 \%$ & $0,8 \%$ & $0,1 \%$ & $0,6 \%$ \\
\hline $\begin{array}{l}\text { Divorciado } \\
\text { Viudo }\end{array}$ & $1,2 \%$ & $9,9 \%$ & $9,3 \%$ & $4,4 \%$ & $6,9 \%$ \\
\hline $\begin{array}{l}\text { Nunca casado / } \\
\text { Otros }\end{array}$ & $0,1 \%$ & $1,2 \%$ & $10,9 \%$ & $37,1 \%$ & $6,8 \%$ \\
\hline NS/NC Th, & $76 \%$ & $19,5 \%$ & $6,0 \%$ & $5,0 \%$ & $29,8 \%$ \\
\hline
\end{tabular}

Tabla 10. Nivel medio de felicidad (IBSE), según edad y estado civil. Europa-27, 2012.

\begin{tabular}{|c|c|c|c|c|c|}
\hline \multirow[b]{2}{*}{ Estado civil } & \multicolumn{4}{|c|}{ EDAD } & \multirow[b]{2}{*}{ TOTAL } \\
\hline & $\begin{array}{l}\text { JÓVEN } \\
(15-34)\end{array}$ & $\begin{array}{l}\text { ADULTO } \\
(35-54)\end{array}$ & $\begin{array}{l}\text { MADURO } \\
(55-74)\end{array}$ & $\begin{array}{l}\text { MAYOR } \\
\text { (75 y más) }\end{array}$ & \\
\hline Casado/Pareja & 12,45 & 5,33 & 5,97 & 1,32 & 5,95 \\
\hline Separado & $(-77,08)$ & $-10,79$ & $-8,41$ & --- & $-14,9$ \\
\hline Divorciado & $-16,33$ & $-5,26$ & $-5,50$ &,- 54 & $-5,65$ \\
\hline Viudo & $(-45,64)$ & $-14,36$ & $-17,8$ & $-16,8$ & $-17,2$ \\
\hline $\begin{array}{l}\text { Nunca casado / } \\
\text { Otros }\end{array}$ & 9,54 & $-3,38$ & $-1,88$ & 1,28 & 5,75 \\
\hline Total & 9,39 & 2,12 & 1,24 & $-5,64$ & 3,18 \\
\hline
\end{tabular}


Tabla 11. Porcentaje de "insatisfechos+infelices", según edad y estado civil. Europa-27, 2012.

\begin{tabular}{|c|c|c|c|c|c|}
\hline \multirow[b]{2}{*}{ Estado civil } & \multicolumn{4}{|c|}{ EDAD } & \multirow[b]{2}{*}{ TOTAL } \\
\hline & $\begin{array}{l}\text { JÓVEN } \\
(15-34)\end{array}$ & $\begin{array}{l}\text { ADULTO } \\
(35-54)\end{array}$ & $\begin{array}{l}\text { MADURO } \\
(55-74)\end{array}$ & $\begin{array}{l}\text { MAYOR } \\
\text { (75 y más) }\end{array}$ & \\
\hline Casado/Pareja & $13,5 \%$ & $16,6 \%$ & $17,7 \%$ & $19,7 \%$ & $16,9 \%$ \\
\hline Separado & $(78,5 \%)$ & $27,4 \%$ & $22,2 \%$ & --- & $29,2 \%$ \\
\hline Divorciado & $30,3 \%$ & $27,3 \%$ & $25,8 \%$ & $18,4 \%$ & $26,4 \%$ \\
\hline Viudo & $(51,1 \%)$ & $29,0 \%$ & $32,3 \%$ & $32,8 \%$ & $32,4 \%$ \\
\hline $\begin{array}{l}\text { Nunca casado / } \\
\text { Otros }\end{array}$ & $15,1 \%$ & $23,4 \%$ & $22,9 \%$ & $18,1 \%$ & $17,5 \%$ \\
\hline Total & $15,4 \%$ & $19,2 \%$ & $20,6 \%$ & $24,5 \%$ & $19,0 \%$ \\
\hline
\end{tabular}

\section{BIBLIOGRAFÍA}

BEJA, E. L. (2018): “The U-shaped relationship between happiness and age: evidence using world values survey data”, Quality \& Quantity, 52(4):1817-1829.

BERICAT, E. (2019): "The Quality of European Societies: An overview", en The Quality of European Societies. A compilation of Composite Indicators, Springer, pp. 27-49

BERICAT, E. (2018): Excluidos de la Felicidad. La estratificación social del bienestar emocional en España, Madrid, CIS.

BERICAT, E. (2014): “The Socioemotional Well-Being Index (SEWBI): Theoretical Framework and Empirical Operationalization”, Social Indicators Research, 108, pp. $1-28$.

BLANCHFLOWER, D. G. y OSWALD, A. J. (2008): "Is well-being U-shaped over the life cycle?", Social Science \& Medicine, 66, pp. 1733-1749

BLANCHFLOWER, D. G. y OSWALD, A. J. (2009): "The U-Shape without control. A response to Glenn", Social Science \& Medicine, 69, pp. 486-488.

CLARK, A. E. and OSWALD, A. J. (2006). "The curved relationship between subjective well-being and age", PSE Working Papers 2006-29, pp. 1-14

DARBONNE, A., UCHINO, B. N., and ONG, A. D. (2013): "What Mediates Links Between Age and Well-being? A Test of Social Support and Interpersonal Conflict as Potential Interpersonal Pathways", Journal of Happiness Studies, 14, pp. 951-963.

DEAR, K., HENDERSON, S., KORTEN, A. (2002): "Well-being in Australia", Social Psychiatry and Psychiatric Epidemiology, 37(11), pp. 503-509.

DIENER, E. et al (1999): "Subjective Well-Being: Three Decades of Progress", Psychological Bulletin, 125(2), pp. 276-302.

DIENER, E. y BISWAS-DIENER, R. (2002): "Will money increase subjective well-being? A literature review and guide to needed research", Social Indicators Research, 57, pp. 119-169. 
EASTERLIN, R. A. (2006): "Life cycle happiness and its sources. Intersections of psychology, economics, and demography", Journal of Economic Psychology, 27, pp. 463-482

FRIJTERS, P. y BEATTON, T. (2012): "The mystery of the U-shape relationships between happiness and age", Journal of Economic Behavior \& Organization, 82, pp. 525-542.

GLENN, N (2009): "Is the apparent U-shape of well-being over the life course a result of inappropriate use of control variables? A commentary on Blanchflower and Oswald", Social Science \& Medicine, 69, pp. 481-485.

JIVRAJ, S., NAZROO, J., VANHOUTTE, T., and CHANDOLA, T. (2013): “Age, aging and subjective wellbeing in later life", Manchester, CCSR, pp. 1-20.

KEMPER, Th. D. (2016): Elementary Forms of Social Relations: Status, power and reference groups, London, Routledge.

KRISTOFFERSEN, I. (2015): "The age-happiness puzzle: the role of economic circumstances and financial satisfaction”, The University of Western Australia, Discussion paper 10.15 , pp.1-40.

LELKES, O. (2008): "Happiness Across the Life Cycle: Exploring Age-Specific Preferences", Policy Brief March (2), European Centre for Social Welfare Policy and Research, pp. 1-15.

LLEDÓ, E. (2011): El epicureísmo. Una sabiduría del cuerpo, del gozo y de la amistad, Madrid, Taurus.

MICHALOS, A. C. (1986): "An application of multiple discrepancies theory (MDT) to seniors", Social Indicators Research, 18(4), pp. 349-373.

MICHALOS, A. C. (2008): "Education, Happiness and Wellbeing", Social Indicators Research, 87(3):347-366.

MORGAN, J., ROBINSON, O., THOMPSON, T. (2015): "Happiness and Age in European Adults: The Moderating Role of Gross domestic Product per Capita", Psychology and aging, 30(3), pp. 544-551.

MROCZEK, D. K. and KOLARZ, C. M. (1998): "The Effect of Age on Positive and Negative Affect: A Developmental Perspective on Happiness", Journal of Personality and Social Psychology, 75(5), pp. 1333-1349.

MROCZEK, D. K. and SPIRO, A. (2005): "Change in Life Satisfaction During Adulthood", Journal of Personality and Social Psychology, 88(1), pp. 189-202.

PICHLER, F. (2006): "Subjective quality of life of young Europeans. Feeling happy but who knows why", Social Indicators Research, 75, pp. 419-444.

ROJAS, M. (2014): El estudio científico de la felicidad, México, Fondo de Cultura Económica.

SAVAGE, M. y BURROWS, R. (2007): "The Coming Crisis of Empirical Sociology", Sociology, 41(5), pp. 855-899.

SCHILLING, O. (2006): "Development of life satisfaction in old age: another view on the "paradox"”, Social Indicators Research, 75, pp. 241-271.

SCHWANDT, H. (2016): "Unmet aspirations as an explanation for the age U-shape in wellbeing", Journal of Economic Behavior \& Organization, 122, pp. 75-87.

SEN, A. (1980): "Description as Choice", Oxford Economic Papers, New Series, Vol. 32 (3), pp. 353-369.

SPRINGER, K.W., PUDROVSKA, T. and HAUSER, R. M. (2011): Does Psychological Well-Being Change with Age? Social Science Research, 40(1), pp. 392-398.

VANHOUTTE, B. (2012): "Measuring subjective well-being in later life: a review. Manchester: CCSR, disponible en: www.ccsr.ac.uk. (acceso:2-12-2018) 
WINKELMANN, L. and WINKELMANn, R. (1998): "Why Are the Unemployed So Unhappy? Evidence from Panel Data", Economica, 65, $\mathrm{N}^{\circ}$ 257, pp. 1-15.

WILSON, W. (1967): "Correlates of avowed happiness", Psychological Bulletin, 67, pp. 294-306. 
